$\underline{\text { Review Article }}$

\title{
NOSE-TO-BRAIN DELIVERY, A ROUTE OF CHOICE FOR TARGETING BRAIN TUMORS
}

\author{
IBRAHIM AMINU SHEHU ${ }^{*}$, MOJAHIDUL ISLAM ${ }^{2}$, VIJENDER SINGH ${ }^{3}$
}

${ }^{1}$ School of Allied Health Science, Sharda University, Knowledge Park III 201306, Greater Noida, UP. India, ${ }^{2}$ School of Pharmaceutical Sciences, Lingayas Vidyapeeth University, Faridabad, India, ${ }^{3}$ Rakshpal Bahadur Pharmacy Institute, Plot No 04, Knowledge Park III 201306, Greater Noida, UP. India

*Email: ibrahimaminushehu@gmail.com

Received: 23 Dec 2020, Revised and Accepted: 13 Mar 2021

\begin{abstract}
Brain tumours are the most lethal type of cancer, which is difficult to manage due to the inherent suboptimal bioavailability of the chemotherapy agent at tumour sites, consequent of high levels of protection of physiological blood-brain barrier (BBB), blood tumour barrier (BTB) and bloodcerebrospinal fluid barrier (CSF). Improving the permeability of these barriers would enhance the disease's clinical prognosis and promote patients' quality of life. To this end, scientists have conducted several studies to determine the most suitable route for CNS delivery. Most of which show that the nose-to-brain is proposed to be the most convenient, efficacious and clinically beneficial non-invasive means of delivering chemotherapeutic agents directly to the brain. Therefore, this study compares the therapeutic benefits of intranasal and other conventional brain delivery systems and further evaluates the clinical benefits of using different nanocarriers for brain tumour targeting. However, we surveyed the literature by conducting an in-depth search of the research keywords and their combinations in recognized scientific databases, primarily Science Direct, PubMed, Google Scholar, and Research Gate. Our findings have shown that the nose-to-brain delivery of chemotherapeutics is a breakthrough in bypassing the effects of BBB, BTB, and CSF barriers, improving the delivery of drugs to the brain for specific tumour targeting with desired clinical prognosis.
\end{abstract}

Keywords: Brain tumours, Glioblastoma, Intranasal route, Conventional delivery, Nanocarriers, Blood-brain barrier, and blood tumor barrier

(C) 2021 The Authors. Published by Innovare Academic Sciences Pvt Ltd. This is an open access article under the CC BY license (https://creativecommons.org/licenses/by/4.0/) DOI: https://dx.doi.org/10.22159/ijap.2021v13i3.40602. Journal homepage: https://innovareacademics.in/journals/index.php/ijap

\section{INTRODUCTION}

Edwin Smith was the first to discuss the central nervous system CNS's concept in his papyrus about 3,600 y ago $[1,2]$. Later, about 1,300 BC, the Ebers' papyrus described the concept of cancer and tumors [3]. Besides, Hippocrates identified some tumors in the crab's legs and called them "karkinos," in Greek words, meaning "crab/cancer," in English [4]. The global brain cancer incidence is higher in men than in women, in developed than under-developed countries with the incidence and mortality rates of 3.4 and 2.5 par 100,000 . Albania has the highest prevalence of 7.5 par 100,000 [5]. It accounts for $3 \%$ of all cancer globally [6]. Nevertheless, the significant risk factors are immune-imbalances, hormones, family history, smoking, alcoholism, in addition to radiation, and ageing [7].

Primarily, CNS tumors have been classified into; pituitary adenomas, gliomas, and primitive or vestibular neuroectodermal tumors, out of which 'glioblastoma multiform' (GBM) emerged as the most lethal type of CNS malignancy with $81 \%$ prevalence [8, 9] and 12-15 mo survival chance [10]. Moreover, the World Health Organization (WHO) graded the tumors into low-grade gliomas (grade I and II) and high-grade gliomas (grade III and IV), respectively [11]. Glioblastoma (high-grade glioma stage IV) is the most lethal type with less than a 5\% survival rate [12], and more than $90 \%$ recurrence chances [13]. Nevertheless, the pattern of metastases and localization of glioblastoma malignancy remains unclear [14]. But, it shows dynamic changes in morphological and structural forms over time [15]. Understanding these concepts will significantly optimize the disease prognosis and increase the survival chances of the affected patients [16]. Henceforth, effective treatment of these malignancies is among the most challenging aspects of the pharmaceutical research field. Because, the bloodbrain barrier (BBB), blood tumor barrier (BTB) and immunoregulatory mechanisms have become the rate-limiting steps for delivering chemotherapeutic agents to CNS [17]. The contemporary management approaches including surgery, radiation therapy [18]. and Temozolomide (TMZ) have shown limited clinical benefits [19]. Bypassing the BBB through an invasive approach (using physical carriers) could compromise brain functions and induce neurotoxicity. Therefore, a non-invasive (carrier-free) approach could increase drug permeability across the BBB to the target tumor [20]. Hence, the study of advances that could enhance drug delivery across these barriers is highly needed[21]. The established literature have proved the effectiveness of chemotherapeutic agents when delivered via the nose-to brain route through olfactory and trigeminal nerves [22]. The clinical benefits of using intranasal delivery outweigh that of other routes [23]. As we discussed in (table 3). However, the molecule meant for brain targeting should be highly lipophilic non-ionized, less than $400 \mathrm{Da}$ molecular weight, with an ionization constant range from 0.5 to 6.0 at physiological PH [24]. Nonetheless, the aforementioned features alone are not enough to provide sufficient pharmacokinetic effects that could permit a molecule to cross BBB efficiently [25]. Although, mucociliary clearance, enzymatic degradation of proteins and peptides result in suboptimal bioavailability of such biomolecule in nasal delivery upon intranasal delivery [26, 27]. Perhaps, overcoming these hurdles will maximize the clinical benefit of the system. Nowadays, the potential technique for chemotherapeutic delivery enhancement for CNS tumor targeting is by encapsulating the drug into nanoparticles and administer them through the intranasal route $[28,29]$. Nanoparticles have owed several advantages of optimization of drug pharmacokinetics to the compromisation of the physiological barriers enhancing the drug concentration at the targeted site [30]. Nevertheless, nano-size features of different NPs boost their transcellular transport proficiency, optimizing the targeted therapy for specified braintumors. Therefore, several NPs have been used as drug carrier vehicles for brain tumor targeting via nasal route [23, 31]. The review evaluates the clinical importance of brain tumor targeting through nasal administration and its therapeutic benefit over conventional delivery systems.

\section{Brain tumors}

Brain tumors have different classification types, most prominently; they have been classified into primary and secondary brain tumors [fig. 1]. 


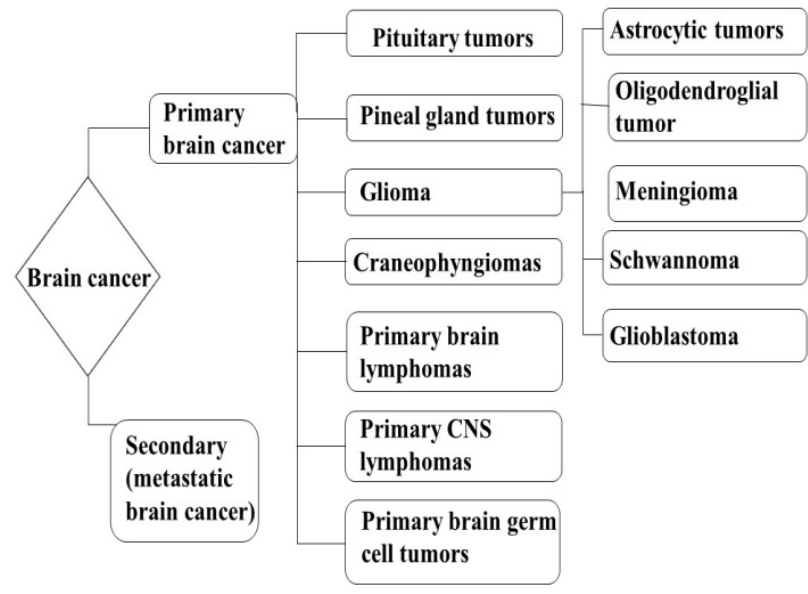

Fig. 1: Classification of brain cancer

The primary tumors were categorized according to their originating tissues; gliomas, primitive, vestibular neuroectodermal, and pituitary adenoma. In contrast, the secondary tumors were characterized as metastatic tumors [32, 33]. The gliomas initiated from glial cells are the predominant types of CNS tumors that are associated with poor prognosis, including glioblastoma multiform (GBMs) which accounted for $81 \%$ of all brain tumors, astrocytoma (AS) oligodendrogliomas (OAs), among others. On the other hand, in 2004, the World Health Organization WHO further classified the CNS tumors based on their histopathological parameters using a four-point grading scale [ IIV] [34] as illustrated in table 1.

Table 1: WHO grading of brain tumors

\begin{tabular}{|c|c|c|c|c|}
\hline WHO & Descriptive features & Members & Criteria & Ref. \\
\hline Grade I & $\begin{array}{l}\text { Slow proliferating non-malignant tumours, } \\
\text { with high survival chances. }\end{array}$ & $\begin{array}{l}\text { angiocentric glioma, pilocytic astrocytoma, } \\
\text { and subependymal giant cell astrocytoma }\end{array}$ & Nil & [35] \\
\hline Grade II & $\begin{array}{l}\text { Slow proliferating tumours with a high- } \\
\text { grade, recurrent tendency, they may be } \\
\text { malignant or non-malignant. }\end{array}$ & $\begin{array}{l}\text { chordoid glioma of the third ventricle, low- } \\
\text { grade diffuse astrocytoma, and cellular } \\
\text { and clear cell ependymoma }\end{array}$ & Cytological atypia (atypical cell) & \\
\hline Grade III & $\begin{array}{l}\text { Malignant tumours that might reoccur as a } \\
\text { high-grade tumour }\end{array}$ & $\begin{array}{l}\text { anaplastic astrocytoma, and anaplastic } \\
\text { oligoastrocytoma }\end{array}$ & Mitotic and activity anaplasia & \\
\hline Grade IV & Proliferate rapidly with high malignancy & Glioblastoma multiform GBM & $\begin{array}{l}\text { Mitotic, activity anaplasia with } \\
\text { necrosis, and microvascular } \\
\text { proliferation }\end{array}$ & \\
\hline
\end{tabular}

\section{Rate limiting barriers for chemotherapeutic delivery to CNS}

Both blood-brain and blood tumor barriers are known as inherent barriers that limit the absorption and transport of molecules between systemic circulation and the brain, which significantly reduces the bioavailability of pharmacological agents, reducing their clinical efficacy in treating various brain infections and disorders. As shown in [fig. 2].

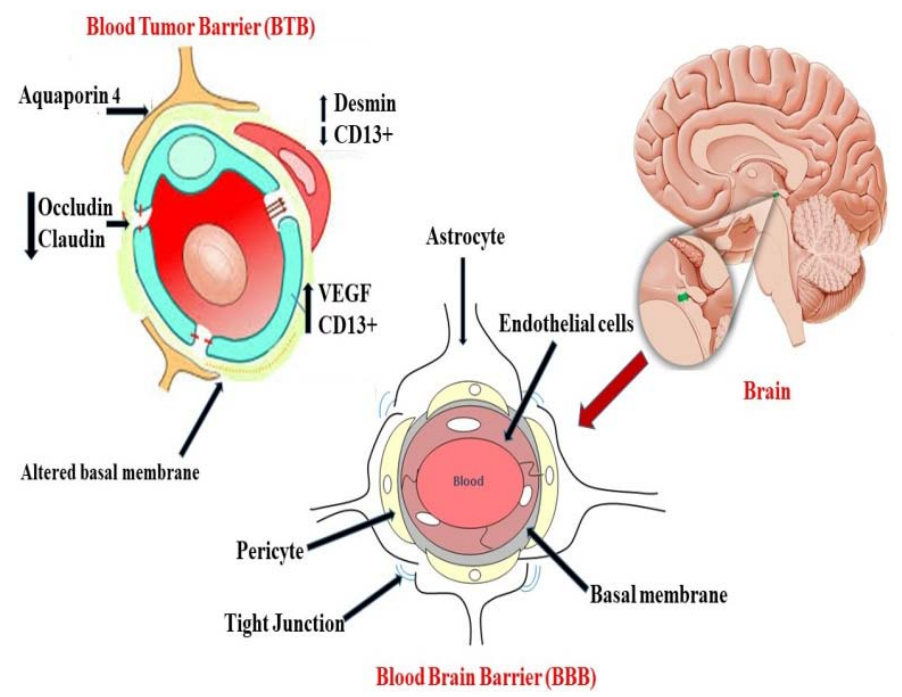

Fig. 2: Blood-brain and blood-tumor barrier 


\section{The blood-brain barrier (BBB)}

Anatomically, the BBB consists of an inner endothelial layer containing several tight junctions composed of claudin and occludin layers encapsulated with the basal membrane and further encircled by the Astrocyte. Pericyte is wrapped in the basal membrane between the outer Astrocyte and the endothelial layer. However, the tight junctions are solely responsible for limiting the paracellular movement of substances across BBB. Whereas the basement membrane augments its protective effectiveness [36-39] However, $\mathrm{BBB}$ is highly selective in nature, allowing only specific molecules with unique physiochemical properties of tiny size (preferably "nano form"), the molecular weight of less than $400 \mathrm{Da}$, ionization of 1.5 to 2.7 and intense hydrogen bonding. These features restrict the entrance of many drugs and bio-molecules into the brain [40-42].

\section{Brain tumour barrier (BTB)}

The brain tumour barrier is a protective layer formed consequent of an anatomical and physiological alteration of BBB, because of the regeneration of new blood vessels that oxygenate the growing tumour through the loosed-tight junctions of the endothelial cells. These newly formed vessels had some tiny pores that prevented the permeation molecules, including hydrophilic ones [43-45]. The affected tissue triggers the release of Vascular Endothelial Growth Factor (VEGF) that facilitated the neoangiogenesis system allowing the tumour to metastases throughout the brain. As a result, these changes further limited the absorption of chemotherapy agents' into the targeted brain tumour [46].

\section{Blood cerebrospinal fluid barrier (BCB)}

Blood Cerebrospinal Fluid Barrier is the rate-limiting step for drugs and molecules absorption from the systemic circulation to CNS. Physiologically, the arrangement of choronoid plexus' epithelium limits the molecular exchange from blood to CSF. Besides, the brain parenchymal cells formed an arachnoid membrane (double layer) between the pia and dura mater, guided by tight junctions that enhance the integrity of the BCB and serve as the drainage system of CSF. However, this barrier the second most preventive barrier after BBB that limits the drug permeation to CNS [47].

\section{Mechanism of intranasal delivery of chemotherapeutic agents}

Studying the anatomy and physiology of the nose and associated nerves are essential for understanding the nose-to-brain delivery mechanisms, useful for developing the ideal formulation for brain targeting [48, 49]. Conversely, the nasal cavity is divided by the lateral and septal walls into two halves, that supplies sensory and olfactory nerves; in which the olfactory nerves extend to the brain [50]. In contrast, the sensory innervation consists of the mandibular, maxillary, and ophthalmic zones of the trigeminal nerve [51]. The entire nose consists of three regions, namely the respiratory, olfactory, and vestibular areas [52] Extension of the olfactory nerve ends in the olfactory bulb (chemosensory zone) where the drug's maximum concentration can be found in the brain. Interestingly, the olfactory bulb is directly connected to the brain, enabling the intraneuronal transport of a particular compound to different parts of the brain. Moreover, the olfactory mucosa supplies the skull in close vicinity to CNS [53]. Unfortunately, the molecules are delivered through an olfactory nerve in a delay pattern. Alternatively, the molecules infiltrate the pre-neural compartment of the cranial nerves and flow to the CSF, from where it permeates to different parts of the brain [54]. However, the trigeminal, olfactory and respiratory epithelia permit therapeutics to distribute to other brain sections. [55] S. Yadav et al. found the intranasal administration of cyclosporine A (CSA) nanoemulsion riches the brain at higher concentrations. It was identified to have reached the brain through the olfactory bulb, hindbrain, and midbrain (via olfactory epithelium) through CSF [56]. R. G. Thorne et al. investigated the rat's CNS pathways involved in delivering insulin-like growth factor-1 (IGF-I) via intranasal route; the researchers identified the two significant ways through which administered insulin [125I] distributed and concentrated in the rats' CNS and CSF. The "peripheral olfactory system" a system that links the nasal stream, olfactory bulbs, and anterior-brain portion. Whereas the "peripheral trigeminal system" channels nasal passage to brain steam and CSF. According to the authors' report, intravenous administration of [125I] to another group revealed similar results with that of intranasal but showed lesser CNS concentration than an intranasal pathway [57]. Shinde et al. investigated the potential for nose-to-brain delivery of atomoxetine (ATX) encapsulated in liposomes using in vivo rat model experiments. Following a gamma scintigraphy examination, the result indicated a significant distribution of the drug in the CNS [58]. Therefore, good pharmacokinetics and physicochemical parameters of the drug determine its suitability for intranasal administration; usually, highly lipophilic unionized drugs that have low molecular weight are the desirable candidates for intranasal administration and hence could pass BBB through all these pathways [59]. As illustrated in [fig. 3].

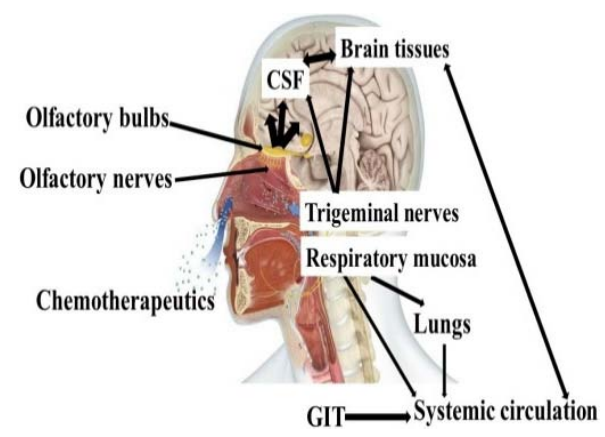

Fig. 3: Mechanism of intranasal delivery of chemotherapeutics

\section{Nanocarriers use for tumor targeting via a nose-to-brain delivery system}

Nanocarriers transport the chemotherapeutic agents crossing BBB via several mechanisms, and they sustainably release the drugs to the brain. However, the FDA approved liposomes and dendrimers as a nanocarrier to deliver pharmacological agents to the brain. They have been widely used for targeting different types of brain disease through surface modification with other polymers and proteins [60, 30]. We summarized the literature of these in [table 2]

\section{Preclinical studies}

\section{In vitro trials}

Several studies have been carried out on the intranasal delivery of chemotherapeutics amongst Jeffrey J, et al.; demonstrated an in vitro experiment on rodents and primates models. The author examined the drug distribution in the rats' perivascular space (PVS) and internal cerebral vessels using fluorescence imaging techniques, and the comparative study showed that the intranasal administration of the drug owed to have high distribution then intravenous administration. Therefore, the result indicated the potentiality of the intranasal route as an alternative way of delivering therapeutics for disease CNS targeting [61]. Khan A prepared and administered Temozolomide chitosan-nano-formulation using the Clone-6 (C6) glioma cell line of Wister rate via intranasal route. A histopathological examination at the end of the study has revealed the high delivery efficiency due to the mucosal effect from the chitosan-nanogel that sustained drug release. Moreover, the drug found to have attained the optimal concentration in the brain [1]. Angel T. Alex, et al;; evaluated the permeation efficiency of the antineoplastic drug (carboplatin), the permeation of both Carboplatin-loaded nanoparticle (CP-NPs) and pure carboplatin formulation was determined using in situ, in vitro, and ex vivo evaluation studies. In an ex vivo study, the authors isolated the new mucosal cell line of sheep and tested the two formulations; the study indicated that the CP-NPs have higher permeation efficiency than the pure formulation. Likewise, the in vitro study was conducted using the CP-NPs formulations, one containing higher and the other holding a lower polymer concentration. After $72 \mathrm{~h}$ of administration to 96-growing human glioblastoma cells, the result indicated the rapid, followed by sustained release pattern in both formulations. Although the formulation that contained the lower polymer concentration has shown to release faster, this demonstrated the 
importance of using fewer polymers in such nano-formulations. However, the in situ evaluation has shown better nasal permeation in CP-NPs then the pure formulation. Overall, the Carboplatin-loaded nanoparticle (CP-NPs) could be a breakthrough for targeting brain tumors using intranasal administration [62]. Kanazawa, T., et al.; evaluated the safety and intranasal delivery efficiency of small interfering (siRNA) incorporated with modified block co-polymersTat nano micelles using rat modal. The in vitro study on glioma C6 cell-lines revealed high tumor inhibition upon intranasal delivery than intravenously injected formulation. Therefore, the author concluded that nose to brain rout is the most suitable means of targeting CNS disorders [63]. Maha N et al. formulated the intranasal Hyaluronic acid-based nanoemulsions of resveratrol and curcumin. The study shows the drug attained high concentration in the rats' CNS due to the mucoadhesive nature and BBB permeation ability in the nasal passage [64]. Co-administration of acetazolamide with 5fluorouracil via intranasal and intravenous routes was evaluated by Author links open overlay panel T. Shingaki, et al. The concomitant administration through nose-to-brain route was found to have enhanced the drug concentration to $104 \%$ and $46 \%$ against intravenous administration of 5-uracil alone [65]. The study conducted by Hee-Yeon, et al.; showed a significant increase in temozolomide's anti-tumour activity (TMZ) after intranasal delivery to the rats bearing TMZ-resistant malignant gliomas. This means that temozolomide (TMZ) intranasal delivery could overcome the resistivity of oral TMZ-resistant malignant gliomas [66].

\section{In vivo trials}

J. H. Azambuja et al. administered siRNA-nanoemulsion intranasally to the Glioblastoma-induced Wister rats; the study's result showed a $60 \%$ reduction of glioblastoma tumor on the tested rat [67]. T. Sakane et al., evaluated the perfusion of 5 -fluorouracil (5FU) in the rats' CSF using in vivo models of wister rats. The authors compared the intranasal and intravenous drug concentration in the CSF. The study result indicated that the drug's high concentration reaches the CNS via CSF upon intranasal delivery than intravenous [65]. Luxiang, et al., conducted an in vivo evaluation of the efficiency of intranasal administration. The authors prepared and administered tyrosine kinase nanoparticles intranasally to glioma-induced rats. Upon examination, the study results indicated a maximum possible reduction in tumour size by facilitating the apoptosis rate, which is then observed in other preparation [68]. M. Colombo et al. evaluated the intranasal delivery of kaempferol-loaded nanoformulation and mucoadhesive nanosuspension using in vivo rat model. Histopathological investigation of the rats treated with both formulations has shown the significant reduction in the size of glioma cells. However, kaempferol nanoemulsion induced apoptosis largely than mucoadhesive nanosuspension [69]. E. Sekerdag, et al. compared the anti-glioma efficacy of $500 \mu$ M PEGlycatedfarnesylthiosalicylic acid (FTA) on Wister rats for ten days intravenous and intranasal administration. After the post-treatment examination, the Nuclear Magnetic Resonance Imaging indicated the $55.7 \%$ reduction in tumor size. According to the study, there is no difference observed upon administering FTA via the intranasal or intravenous route. Matthias Van et al. encapsulated the small interfering RNA (siRNA) in chitosan nanoparticles and administered it into Glioblastoma-induced mouse intranasally. The author treated the mouse with the prepared formulation for days $5,8,12$, and 15 . However, the immunofluorescence test performed on the 5 the day post-treatment showed a significant reduction in tumor size. The author further observed high concentration of drug in olfactory bulbus upon in vitro intranasal delivery via the olfactory pathway (from where the drug possibly distributes directly to the CNS) [70]. Darshana S. et al. administered both pure and Polylactic Acid (PLA) suspended nanoparticles of methotrexate via the intranasal route of two sub-grouped mice, each containing six members. The first group was treated with pure methotrexate has shown low bioavailability because the drug is highly hydrophilic in nature; consequently, it cannot cross BBB. On the other hand, the second group treated with PLA-methotrexate NPs has shown significant CNS concentration in both in vitro and in vivo evaluation after the pharmacokinetics evaluation. This is because the Polylactic Acid nanosuspension has the sol-gel-sol property that increases MTX's mucosal residence time; hence, the BBB penetration and CNS distribution. Lastly, the cytotoxic evaluation has shown no difference in toxicity between both the study participants. However, the authors proposed thermosensitive nanoformulation to be a gold standard for the formulation of antineoplastic drugs intended to target CNS tumors through the nose-to-brain route. [71] A. Mangraviti, et al. have developed the polymeric nanoparticles incorporated with plasmid DNA to transfect "Human adipose-derived mesenchymal stem cells" (hAMSCs) through the intranasal route of glioma infected rats, as an alternative to viral transduction system. The in vitro evaluation revealed the significant reduction in glioma cells size more efficiently than the usual viral transduction method. While the in vivo experiment has indicated the possibility of high viability among the glioma bearing rats [72]. Hiroyuki Taki, et al. evaluated the antitumour and safety effect of camptothecin (CPT)-nano-micelles on intranasal administration using glioma infected rats. The in vivo investigation revealed evidence of tumour-shrinking and high viability chances on the treated rats. The author established the safety of the formulation at a high dose of $2 \mathrm{mmol} / \mathrm{ml}$ [73]. According to the sun et al. report, the CNS concentration of Methotrexate (MTX) encapsulated in chitosan microspheres was determined to be $118 \%$ upon intranasal administration to healthy Wister rats. While it was remained undetected when administered intravenously. [74] The study conducted by Pineda JR, et al.; proved the effectiveness of intranasal infusion of Temozolomide (TMZ) as anti-glioblastoma in nude mice. After the drug administration 3times a week for two weeks, a remarkable reduction in tumor size without alteration in the mice's sense of smell was observed [75].

\section{Clinical studies for intranasal brain tumor targeting}

DA Fonseca et al. performed a clinical evaluation for the effectiveness of intranasal administration of "perillyl alcohol" (POH) on 152,26 , and 5 different patients with a primary glioblastoma GBM, astrocytoma grade III AA and anaplastic oligodendroglioma $\mathrm{AO}$, respectively. The drug was intranasally administered to the patients 4 times daily, initiating a minimal dose of $66.7 \mathrm{mg} /$ dose, and titrated to $533.6 \mathrm{mg} /$ day. The study outcome after $4 \mathrm{y}$ of the study indicated a favourable prognosis among the tested patients. However, $19 \%$ of them have been clinically under remission. Although $95 \%$ of the patients have developed rare nasal bleeding and soreness [76]. C. Fonseca, et al. conducted a phase I/II clinical trial to access the safety profile of Perillyl alcohol (POH) on patients with relapsed malignant glioma. The author was administered the intranasal dose of $0.3 \% \mathrm{vol} / \mathrm{vol}$ containing $55 \mathrm{mg} \mathrm{POH} 4$ times daily and consecutively to 37 patients who had sub-grouped into 29 with Glioblastoma, 3 with anaplastic oligodendroglioma and 5 with astrocytoma grade III, for the period of 6 mo. Upon completing the cohort study, the preliminary result indicated the safety, reliability, and non-invasive anti-tumor efficacy of $\mathrm{POH}$. Clovis Fonseca, et al. had performed a clinical analysis on 67 patients with brain tumors the study evaluated the effectiveness of intranasal chemotherapy with Perillyl alcohol ( $\mathrm{POH})$ among glioma patients. The relationship between tumor size, localization, and relative treatment prognosis has been observed. Throughout the study period, the patients were categorized into some groups, in which 52,10 , and 5 patients bearing GBM, AA, and OA were recruited, respectively. A daily dose of $440 \mathrm{mg} \mathrm{POH}$ was maintained among the recruited patients. The author observed the longer survival chances and the promising clinical prognosis among the patients bearing recurrent malignant glioma, while those having lobar localization and peritumoral oedema have shown poor prognosis and low survival chances. Therefore, the study indicated the safety and tolerability of noninvasive chemotherapy and evident the definite relationship between the tumor localization and clinical prognosis among glioma patients [78]. Clovis 0. et al. the study on 62-year-old anaplastic oligodendroglioma patients revealed the notable reduction in tumor proliferation following the four times daily administration of $10.3 \%$ POH intranasally [79]. However, the Brazil trial further affirmed the clinical safety, tolerance, and efficacy of intranasal $\mathrm{POH}$, in a study that recruited 37 recurrent malignant glioma-bearing patients; these patients were treated with four times daily intranasal $0.3 \% \mathrm{POH}$ for several days [80]. Chen TC et al. evaluated the safety and anti-tumor activity of $\mathrm{POH}$ in a clinical trial phase I/II among the patients with recurrent Glioblastoma. The patient has received 4-times daily intranasal $\mathrm{POH}$ for 6months; the trial evidenced the maximum shrinkage in the bearing patients' tumor size with no toxicity and 
unwanted side effect [81]. Juliana et al. studied the clinical implication of POH's concomitant administration and ketotic diet among 32 patients with recurrent Glioblastoma. After four times daily intranasal administration of $\mathrm{POH}, 17$ with ketotic and 15 without ketotic diet for a period of 3 month. Subsequent clinical investigation of the recruited patients, most of the patients who received the concomitant chemotherapy of $\mathrm{POH}$ with ketotic diet, shows significant tumor inhibition with no toxicity [82].

Table 2: Nanocarriers use for tumor targeting via the nose-to-brain delivery system

\begin{tabular}{|c|c|c|c|c|c|}
\hline Nanoparticles & Shape and size & Mechanism of BBB circumvention & Features & Limitations & Ref. \\
\hline Liposomes & $\begin{array}{l}\text { Spherical, } \\
\text { concentric, Size } \\
50-100 \mu \mathrm{m}\end{array}$ & $\begin{array}{l}\text { Liposomes delivered the drug to the } \\
\text { brain by permeating across the } \\
\text { endothelial cells via endocytosis }\end{array}$ & $\begin{array}{l}\text { bi-layered, phospholipids that } \\
\text { can entrap both hydrophilic and } \\
\text { hydrophobic drugs and it } \\
\text { possessed different surface } \\
\text { charges }\end{array}$ & $\begin{array}{l}\text { Expensiveness, low } \\
\text { drug loading capacity, } \\
\text { and long term stability }\end{array}$ & [83] \\
\hline Solid lipid & $\begin{array}{l}\text { spherical in } \\
\text { shape } 1 \text { and } \\
1000 \mathrm{~nm}\end{array}$ & $\begin{array}{l}\text { It can permeate through the tight- } \\
\text { junctions of the endothelium via a } \\
\text { transcellular pathway and pass } \\
\text { across the BBB }\end{array}$ & $\begin{array}{l}\text { High drug loading efficiency, } \\
\text { control releasing overcome the } \\
\text { effect of mucociliary clearance } \\
\text { and nasal degradation }\end{array}$ & $\begin{array}{l}\text { High water content ( } 70 \\
\text { to } 99.9) \% \text {, Undesired } \\
\text { drug load, leakage } \\
\text { during storage }\end{array}$ & [84] \\
\hline Polymeric NPs & $\begin{array}{l}10-1000 \mathrm{~nm} \\
\text { spherical or } \\
\text { elongated }\end{array}$ & $\begin{array}{l}\text { Polymeric NPs lodges the } \\
\text { chemotherapeutic drug in the brain } \\
\text { through passive or active } \\
\text { transportation }\end{array}$ & $\begin{array}{l}\text { Higher polydispersity index, } \\
\text { stability, biocompatible } \\
\text { biodegradable non-toxic, non- } \\
\text { immunogenic and Inexpensive }\end{array}$ & $\begin{array}{l}\text { Clinical application is } \\
\text { limited by uncertain } \\
\text { toxicity }\end{array}$ & [85] \\
\hline Nanoemulsion & globular size & $\begin{array}{l}\text { Improve mucosal absorption and } \\
\text { overcome nasal mucociliary } \\
\text { clearance }\end{array}$ & $\begin{array}{l}\text { Highly lipophilic, and } \\
\text { permeation, low spherical size, }\end{array}$ & $\begin{array}{l}\text { Unavailability of } \\
\text { intranasal product, }\end{array}$ & [86] \\
\hline Chitosan & $\begin{array}{l}3.2-3.5 \mu \mathrm{m} \text { in } \\
\text { diameter }\end{array}$ & $\begin{array}{l}\text { The increase in temperature enhances } \\
\text { the gel formation and positive charges } \\
\text { of chitosan interact with the negative } \\
\text { charge of the mucosa that results in } \\
\text { excellent retention and paracellularly } \\
\text { cross the tight junctions of epithelial } \\
\text { cells of BBB }\end{array}$ & $\begin{array}{l}\text { Biodegradable, } \\
\text { thermoresponsive, ease } \\
\text { preparation, low toxicity, high } \\
\text { stability and CNS delivery }\end{array}$ & Poor aqueous solubility & $\begin{array}{l}{[87,} \\
88]\end{array}$ \\
\hline Dendrimers & $\begin{array}{l}\text { three- } \\
\text { dimensional } \\
\text { structure of } \\
\text { globular shape. }\end{array}$ & $\begin{array}{l}\text { The penetration efficiency of } \\
\text { dendrimers potentiates by } \\
\text { conjugation with transferrin, D- } \\
\text { glucosamine, leptin, and lactoferrin. } \\
\text { The release depends on the PH and } \\
\text { ionic strength of the media. }\end{array}$ & $\begin{array}{l}\text { Undergo compositional changes } \\
\text { in response to the } \\
\text { environmental condition, wide } \\
\text { therapeutic applications }\end{array}$ & $\begin{array}{l}\text { Extremely low water- } \\
\text { soluble }\end{array}$ & [89] \\
\hline
\end{tabular}

\section{CONCLUSION}

It is no gainsaying that brain cancer is a severe disease characterized by an inferior clinical prognosis. There are overall limited survival chances for brain cancer patients perhaps; the patients bearing Glioblastoma multiform (GBM) are more clinically affected since their survival chances are no longer than 15 mo. Nevertheless, the optimum concentration of active drugs at the brain's targeted site is a prerequisite for effectively managing the disease or disorder. Unfortunately, several anatomical and physiological barriers need to be overcome before the therapeutic agent could reach the brain. Most importantly, blood-brain (BBB), blood tumor barriers (BTB), and blood-cerebrospinal fluid barrier BCB. The choice of the suitable route of administering such drugs became very challenging; the oral, intravenous, and intrathecal routes have failed to provide the desired bioavailability. However, the non-invasive course for delivering chemotherapeutics to the brain to target various CNS tumors needs to be studied. The nose-to brain delivery was an alternative route for delivering anticancer drugs to CNS, being noninvasive and highly efficient in bypassing the blood-brain and brain tumor barriers while limiting the systemic side effects.

Although the intranasal delivery mechanism is not well understood several investigations have demonstrated the drug to have reached the brain mainly through the olfactory and trigeminal nerves. However, incorporating nanoparticle and materials in the drug formulations has further enhanced the drug permeation across the BBB via the nose-to-brain route. Nevertheless, an extensive study on brain tumor targeting via the nose to brain rout will provide sufficient knowledge to aid the drug development and therapeutic outcomes of devastating brain tumors and other disorders. Therefore, nose-to-brain delivery of chemotherapeutics serves as the breakthrough for bypassing the effect of BBB, BTB, and CSF barriers. For that reason, designing the chemotherapeutics agents in the form of inhalational nanoformulation will enhance the clinical prognosis of CNS tumors and the patients' quality of life.

\section{ACKNOWLEDGEMENT}

I acknowledged my parent, teachers, and colleagues' effect forgiven me unflinching support and guidance in my personal and academic affairs.

\section{FUNDING}

Nil

\section{AUTHORS CONTRIBUTIONS}

All the authors have contributed equally.

\section{CONFLICT OF INTERESTS}

The author declared nil conflict of interest

\section{REFERENCES}

1. JEX HS. The edwin smith surgical papyrus: first milestone in the march of medicine. Merck Rep 1951;60:20-2

2. US. National Library of Medicine. Edwin Smith Papyrus. Turn. Pages Online; 2015.

3. The Papyrus Ebers. Translated from the german version. J Am Med Assoc 1932;89:348, 1927.

4. Sudhakar A. History of cancer, ancient and modern treatment methods. J Cancer Sci Ther 2009;1:1-4.

5. Siri FH, Salehiniya H. Pancreatic cancer in iran: an epidemiological review. J Gastrointest Cancer 2020;51:418-24.

6. Miranda Filho A, Piñeros M, Soerjomataram I, Deltour I, Bray F. Cancers of the brain and CNS: Global patterns and trends in incidence. Neuro Oncol 2017;19:270-80. 
7. McKean Cowdin R, Razavi P, Preston Martin S. Brain tumors. Int Encycl Public Health; 2016.

8. Alifieris C, Trafalis DT. Glioblastoma multiforme: pathogenesis and treatment. Pharmacol Ther 2015;152:63-82.

9. Hanif F, Muzaffar K, Perveen K, Malhi SM, Simjee SU. Glioblastoma multiforme: A review of its epidemiology and pathogenesis through clinical presentation and treatment. Asian Pac J Cancer Prev 2017;18:3-9.

10. Thakkar JP, Dolecek TA, Horbinski C, Ostrom QT, Lightner DD, Barnholtz Sloan JS, et al. Epidemiologic and molecular prognostic review of glioblastoma. Cancer Epidemiol Biomarkers Prev 2014;23:1985-96.

11. Patel AP, Fisher JL, Nichols E, Abd-Allah F, Abdela J, Abdelalim A, et al. Global, regional, and national burden of brain and other CNS cancer, 1990-2016: a systematic analysis for the global burden of disease study 2016. Lancet Neurol 2019;8:459-80.

12. Claus EB, Walsh KM, Wiencke JK, Molinaro AM, Wiemels JL, Schildkraut JM, et al. Survival and low-grade glioma: the emergence of genetic information. Neurosurg Focus 2015;38:E6.

13. Morsy AA, Ng WH oe. Re-do craniotomy for recurrent glioblastoma. CNS Oncol 2015;4:55-7.

14. Gangemi RMR, Griffero F, Marubbi D, Perera M, Capra MC, Malatesta $\mathrm{P}$, et al. SOX2 silencing in glioblastoma tumorinitiating cells causes stop of proliferation and loss of tumorigenicity. Stem Cells 2009;27:40-8.

15. Zhang Q, Xiang W, Yi DY, Xue BZ, Wen WW, Abdelmaksoud A, et al. Current status and potential challenges of mesenchymal stem cell-based therapy for malignant gliomas. Stem Cell Res Ther 2018;93:19-31.

16. Mughal AA, Zhang L, Fayzullin A, Server A, Li Y, Wu Y, et al. Patterns of Invasive growth in malignant gliomas-the hippocampus emerges as an invasion-spared brain region. Neoplasia U S 2018;20:643-56.

17. Spadoni I, Fornasa G, Rescigno M. Organ-specific protection mediated by cooperation between vascular and epithelial barriers. Nat Rev Immunol 2017;12:761-73.

18. Wang H, Cai S, Ernstberger A, Bailey BJ, Wang MZ, Cai W, et al. Temozolomide-mediated DNA methylation in human myeloid precursor cells: Differential involvement of intrinsic and extrinsic apoptotic pathways. Clin Cancer Res 2013;19:2699-709.

19. Tiek DM, Rone JD, Graham GT, Pannkuk EL, Haddad BR, Riggins RB. Alterations in cell motility, proliferation, and metabolism in novel models of acquired temozolomide resistant glioblastoma. Sci Rep 2018;8:7222.

20. Sekerdag E, Lule S, Bozdag Pehlivan S, Ozturk N, Kara A, Kaffashi A, et al. A potential non-invasive glioblastoma treatment: nose-to-brain delivery of farnesylthiosalicylic acid incorporated hybrid nanoparticles. J Controlled Release 2017;261:187-98.

21. Angeli E, Nguyen TT, Janin A, Bousquet G. How to make anticancer drugs cross the blood-brain barrier to treat brain metastases. Int J Mol Sci 2020;21:1-16.

22. Tucker C, Tucker L, Brown K. The intranasal route as an alternative method of medication administration. Crit Care Nurse 2018;38:26-31.

23. Bruinsmann FA, Vaz GR, De Cristo Soares Alves A, Aguirre T, Pohlmann AR, Guterres SS, et al. Nasal drug delivery of anticancer drugs for the treatment of glioblastoma: preclinical and clinical trials. Molecules. 2019;24:4312.

24. Begley DJ. Delivery of therapeutic agents to the central nervous system: the problems and the possibilities. Pharmacol Ther 2004;104:29-45.

25. Begley DJ, Brightman MW. Structural and functional aspects of the blood-brain barrier. Prog Drug Res 2003;61:39-78.

26. Comfort C, Garrastazu G, Pozzoli M, Sonvico F. Opportunities and challenges for the nasal administration of nanoemulsions. Curr Top Med Chem 2015;15:356-68.

27. Lee VHL. Enzymatic barriers to peptide and protein absorption. Crit Rev Ther Drug Carrier Syst 1988;5:69-97.

28. Pohlmann AR, Fonseca FN, Paese K, Detoni CB, Coradini K, Beck $\mathrm{RC}$, et al. Poly( $\varepsilon$-caprolactone) microcapsules and nanocapsules in drug delivery. Expert Opin Drug Delivery 2013;10:623-38.

29. Frank LA, Contri RV, Beck RCR, Pohlmann AR, Guterres SS. Improving drug biological effects by encapsulation into polymeric nanocapsules. Wiley Interdiscip Rev Nanomed Nanobiotechnol 2015;7:623-39.

30. Sasi S, Joseph SK, Arian AM, Thomas S, VUA, GKA, et al. An updated review on the application of dendrimers as successful nanocarriers for brain delivery of therapeutic moieties. Int J Appl Pharm 2021;13:1-9.

31. Mistry A, Stolnik S, Illum L. Nanoparticles for direct nose-tobrain delivery of drugs. Int J Pharm 2009;379:146-57.

32. Ostrom QT, Gittleman H, Liao P, Vecchione Koval T, Wolinsky Y, Kruchko C, et al. CBTRUS statistical report: primary brain and other central nervous system tumors diagnosed in the United States in 2010-2014. Neuro-Oncol 2017;19:1-88.

33. Molnar P. Classification of primary brain tumors: molecular aspects. In: Garami M. editor. Manag CNS Tumors. InTech; 2011. Available from: http://www.intechopen.com/books/management-of-cnstumors/classification-of-primary-brain-tumors-molecularaspects [Last accessed on 11 Sep 2020]

34. Nilsson J, Holgersson G, Carlsson T, Henriksson R, Bergström S, Bergqvist $M$. Incidence trends in high-grade primary brain tumors in males and females. Oncol Lett 2017;13:2831-7.

35. Rezaee A. WHO grading of CNS tumors | Radiology Reference Article | Radiopaedia.org. Radiopaedia. Available from: https://radiopaedia.org/articles/who-grading-of-cns-tumours [Last accessed on 11 Sep 2020]

36. Janzer RC, Raff MC. Astrocytes induce blood-brain barrier properties in endothelial cells. Nature 1987;325:253-7.

37. Bicker J, Alves G, Fortuna A, Falcao A. Blood-brain barrier models and their relevance for a successful development of CNS drug delivery systems: a review. Eur J Pharm Biopharm 2014;87:409-32.

38. Liu S, Agalliu D, Yu C, Fisher M. The role of pericytes in bloodbrain barrier function and stroke. Curr Pharm Des 2012;18:3653-62.

39. Abbott NJ, Ronnback L, Hansson E. Astrocyte-endothelial interactions at the blood-brain barrier. Nat Rev Neurosci 2006; 7:41-53.

40. Mc Carthy DJ, Malhotra M, O'Mahony AM, Cryan JF, O'Driscoll $\mathrm{CM}$. Nanoparticles and the blood-brain barrier: advancing from in vitro models towards therapeutic significance. Pharm Res 2015;32:1161-85.

41. Pajouhesh H, Lenz GR. Medicinal chemical properties of successful central nervous system drugs. NeuroRx 2005;2:54153.

42. Warren KE. Beyond the blood: brain barrier: the importance of central nervous system (CNS) pharmacokinetics for the treatment of CNS tumors, including diffuse intrinsic pontine glioma. Front Oncol 2018;8:239.

43. Ganipineni LP, Danhier F, Preat V. Drug delivery challenges and future of chemotherapeutic nanomedicine for glioblastoma treatment. J Controlled Release Elsevier 2018;281:42-57.

44. Li M, Luo Z, Xia Z, Shen X, Cai K. Time-sequenced drug delivery approaches towards effective chemotherapeutic treatment of glioma. Mater Horiz 2017;4:996-77.

45. Lyday RW, Etters AM, Kim C, Magana F, Pontipiedra GM, Singh NKM, et al. PDE5 inhibitors offer novel mechanisms in combination and solo cancer therapy. Curr Cancer Ther Rev 2017;13:107-19.

46. Liu Y, Lu W. Recent advances in brain tumor-targeted nano-drug delivery systems. Expert Opin Drug Delivery 2012;9:671-86.

47. Drug delivery to the central nervous system: a review. Available from: https://sites.ualberta.ca/ csps/ JPPS6/ A.misra/delivery.htm [Last accessed on 13 Sep 2020]

48. Yokoyama Y, Kono T, Aoki M. [A case of allergic granulomatous angitis (author's transl)]. Nihon Naika Gakkai Zasshi J Japan Soc Intern Med 1975;64:565-73.

49. Einer Jensen N, Hunter R. Counter-current transfer in reproductive biology. Reproduction 2005;129:9-18.

50. Guynn RW, Pieklik JR. Dependence on dose of the acute effects of ethanol on liver metabolism in vivo. J Clin Invest 1975;56:1411-9.

51. Schmoldt A, Benthe HF, Haberland G. Digitoxin metabolism by rat liver microsomes. Biochem Pharmacol 1975;24:1639-41. 
52. Fowler NO, McCall D, Chou TC, Holmes JC, Hanenson IB. Electrocardiographic changes and cardiac arrhythmias in patients receiving psychotropic drugs. Am J Cardiol 1976;37:223-30.

53. Pogodina VV. Elizaveta nilolaevna levkovich. $75^{\text {th }}$ birthday. Acta Virol 1975;19:509.

54. Goss DJ, Parkhurst LJ, Gorisch H. Kinetic light scattering studies on the dissociation of hemoglobin from lumbricus terrestris. Biochemistry 1975;14:5461-4.

55. Lochhead JJ, Davis TP. Perivascular and perineural pathways involved in brain delivery and distribution of drugs after intranasal administration. Pharmaceutics 2019;11:598.

56. Yadav S, Gattacceca F, Panicucci R, Amiji MM. Comparative biodistribution and pharmacokinetic analysis of cyclosporine-a in the brain upon intranasal or intravenous administration in an oil-in-water nanoemulsion formulation. Mol Pharm Am Chem Soc 2015;12:1523-33.

57. Thorne RG, Pronk GJ, Padmanabhan V, Frey WH. Delivery of insulin-like growth factor-I to the rat brain and spinal cord along olfactory and trigeminal pathways following intranasal administration. Neuroscience 2004;127:481-96.

58. Vaidya AV, Shinde UA, Shimpi HH. Preliminary studies on brain targeting of intranasal atomoxetine liposomes. Int J Pharm Pharm 2016;7:286-92.

59. Lim ST, Forbes B, Berry DJ, Martin GP, Brown MB. In vivo evaluation of novel hyaluronan/chitosan microparticulate delivery systems for the nasal delivery of gentamicin in rabbits. Int J Pharm 2002;231:73-82.

60. Rajendran R, Balan R, Ganesan N, Thiruvengadam D. Recent modalities in drug delivery via inhalation therapy-an advanced treatment strategy for pulmonary carcinoma. Int J Pharm Pharm 2015;7:8-21.

61. Lochhead JJ, Wolak DJ, Pizzo ME, Thorne RG. Rapid transport within cerebral perivascular spaces underlies widespread tracer distribution in the brain after intranasal administration. J Cereb Blood Flow Metab 2015;35:371-81.

62. Alex AT, Joseph A, Shavi G, Rao JV, Udupa N. Development and evaluation of carboplatin-loaded PCL nanoparticles for intranasal delivery. Drug Delivery 2016;23:2144-53.

63. Kanazawa T, Morisaki K, Suzuki S, Takashima Y. Prolongation of life in rats with malignant glioma by intranasal siRNA/Drug codelivery to the brain with cell-penetrating peptide-modified micelles. Mol Pharm 2014;11:1471-8.

64. Nasr M. Development of an optimized hyaluronic acid-based lipidic nanoemulsion co-encapsulating two polyphenols for nose to brain delivery. Drug Delivery 2016;23:1444-52.

65. Sakane T, Yamashita S, Yata N, Sezaki H. Transnasal delivery of 5fluorouracil to the brain in the rat. J Drug Target 1999;7:233-40.

66. Cho HY, Wang W, Jhaveri N, Torres S, Tseng J, Leong MN, et al. Perillyl alcohol for the treatment of temozolomide-resistant gliomas. Mol Cancer Ther 2012;11:2462-72.

67. Azambuja JH, Schuh RS, Michels LR, Gelsleichter NE, Beckenkamp LR, Iser IC, et al. Nasal administration of cationic nanoemulsions as CD73-siRNA delivery system for glioblastoma treatment. Thera Approach Mol Neurobiol 2020;57:635-49.

68. Chu L, Wang A, Ni L, Yan X, Song Y, Zhao M, et al. Nose-to-brain delivery of temozolomide-loaded PLGA nanoparticles functionalized with anti-EPHA3 for glioblastoma targeting. Drug Delivery 2018;25:1634-41.

69. Colombo M, Figueiro F, de Fraga Dias A, Teixeira HF, Battastini AMO, Koester LS. Kaempferol-loaded mucoadhesive nanoemulsion for intranasal administration reduces glioma growth in vitro. Int J Pharm 2018;543:214-23.

70. Van Woensel M, Wauthoz N, Rosiere R, Mathieu V, Kiss R, Lefranc F, et al. Development of siRNA-loaded chitosan nanoparticles targeting galectin-1 for the treatment of glioblastoma multiforme via intranasal administration. J Controlled Release 2016;227:71-81.

71. Jain DS, Bajaj AN, Athawale RB, Shikhande SS, Pandey A, Goel PN, et al. Thermosensitive PLA based nanodispersion for targeting brain tumor via intranasal route. Mater Sci Eng C 2016;63:411-21.

72. Mangraviti A, Tzeng SY, Gullotti D, Kozielski KL, Kim JE, Seng M, et al. Non-virally engineered human adipose mesenchymal stem cells produce BMP4, target brain tumors, and extend survival. Biomaterials 2016;100:53-66.

73. Taki H, Kanazawa T, Akiyama F, Takashima Y, Okada H. Intranasal delivery of camptothecin-loaded tat-modified nanomicells for treatment of intracranial brain tumors. Pharmaceuticals 2012;5:1092-102.

74. Sun Y, Shi K, Wan F, Cui F. Methotrexate-loaded microspheres for nose to brain delivery: in vitro/in vivo evaluation. J Drug Delivery Sci Technol 2012;22:167-74.

75. Jr P, M J, A A, Mp J, H C, Boussin FD. Intranasal administration of temozolomide delayed the development of brain tumors initiated by human glioma stem-like cell in nude mice. I Cancer Sci Ther; 2017. p. 9. Available from: https://www.omicsonline.org/open-access/intranasaladministration-of-temozolomide-delayed-the-developmentofbrain-tumors-initiated-by-human-glioma-stemlike-cell-innude-m-1948-5956-1000445. php?aid=87652 [Last accessed on 07 Sep 2020].

76. DA Fonseca CO, Teixeira RM, Silva JCT, DE Saldanha DA Gama Fischer J, Meirelles OC, Landeiro JA, et al. Long-term outcome in patients with recurrent malignant glioma treated with perillyl alcohol inhalation. Anticancer Res 2013;33:5625-31.

77. Da Fonseca CO, Schwartsmann G, Fischer J, Nagel J, Futuro D, Quirico Santos T, et al. Preliminary results from a phase I/II study of perillyl alcohol intranasal administration in adults with recurrent malignant gliomas. Surgical Neurol 2008;70:259-66.

78. Fonseca COD, Silva JT, Lins IR, Simao M, Arnobio A, Futuro D, et al. Correlation of tumor topography and peritumoral edema of recurrent malignant gliomas with therapeutic response to intranasal administration of perillyl alcohol. Invest New Drugs 2009;27:557-64.

79. Da Fonseca CO, Masini M, Futuro D, Caetano R, Rocha Gattass C, Quirico Santos T. Anaplastic oligodendroglioma responding favorably to intranasal delivery of perillyl alcohol: a case report and literature review. Surg Neurol 2006;66:611-5.

80. da Fonseca CO, Schwartsmann G, Fischer J, Nagel J, Futuro D, Quirico Santos T, et al. Preliminary results from a phase I/II study of perillyl alcohol intranasal administration in adults with recurrent malignant gliomas. Surg Neurol 2008;70:259-66.

81. Chen TC, Da Fonseca CO, Schönthal AH. Intranasal perillyl alcohol for glioma therapy: molecular mechanisms and clinical development. Int J Mol Sci 2018;19:3905.

82. Santos J, Da Cruz WM, Schinthal A, Salazar M, Fontes CA, Quirico Santos T, et al. efficacy of a ketogenic diet with concomitant intranasal perillyl alcohol as a novel strategy for the therapy of recurrent glioblastoma. Oncol Lett 2017. Available from: http://www.spandidos-publications.com/ 10.3892/ol.2017.7362 [Last accessed on 17 Sep 2020].

83. Patel A, Surti N, Mahajan A. Intranasal drug delivery: Novel delivery route for effective management of neurological disorders. J Drug Delivery Sci Technol 2019;52:130-7.

84. Bhardwaj A, Arora R. Nanoformulations: a novel approach against hypoxia. Manag High Alt Pathophysiol. Elsevier; 2018. p. 231-56. Available from: https://linkinghub.elsevier.com/ retrieve/pii/B9780128139998000124 [Last accessed on 12 Sep 2020].

85. Sardoiwala MN, Kaundal B, Roy Choudhury S. Development of engineered nanoparticles expediting diagnostic and therapeutic applications across blood-brain barrier. Handb Nanomater Ind Appl Elsevier; 2018. p. 696-709. Available from: https://linkinghub.elsevier.com/retrieve/pii/B9780128133514 000389 [Last accessed on 12 Sep 2020].

86. Chatterjee B, Gorain B, Mohananaidu K, Sengupta P, Mandal UK, Choudhury $\mathrm{H}$. Targeted drug delivery to the brain via intranasal nanoemulsion. Int J Pharm 2019;565:258-68.

87. Ansari R, Sadati SM, Mozafari N, Ashrafi H, Azadi A. Carbohydrate polymer-based nanoparticle application in drug delivery for CNS-related disorders. Eur Polym J 2020;128:109607. 
88. Agrawal M, Saraf S, Saraf S, Dubey SK, Puri A, Gupta U, et al. Stimuli-responsive In situ gelling system for nose-to-brain drug delivery. J Controlled Release 2020;327:235-65.
89. Tsai HC, Imae T. Fabrication of dendrimers toward biological application. Prog Mol Biol Transl Sci Elsevier; 2011. p. 101-40. Available from: https://linkinghub.elsevier.com/retrieve/ pii/B9780124160200000036 [Last accessed on 12 Sep 2020]. 